\title{
TOPOLOGI METRIK PARSIAL
}

\author{
DESY WAHYUNI \\ Program Studi Matematika, \\ Fakultas Matematika dan Ilmu Pengetahuan Alam, Universitas Andalas Padang, \\ Kampus UNAND Limau Manis Padang, Indonesia \\ deedees_shyu@yahoo.com
}

\begin{abstract}
Abstrak. Metrik $d$ di himpunan $U$ adalah suatu fungsi jarak sedemikian sehingga aksioma metrik terpenuhi. Suatu metrik parsial di $U$ merupakan generalisasi minimal dari aksioma metrik sedemikian sehingga setiap objek di $U$ tidak perlu harus mempunyai nol jarak dari dirinya sendiri. Topologi metrik parsial adalah topologi yang dibangun oleh basis bola buka metrik parsial, $\mathfrak{B}=\left\{B_{\varepsilon}^{p}(a) \mid a \in U, \varepsilon>0\right\}$. Topologi metrik parsial dinotasikan dengan $\mathcal{T}[p]$. Salah satu ruang topologi dinotasikan dengan $T_{0}$-ruang. Himpunan $\left(U, \ll_{p}\right)$ adalah himpunan urutan parsial atas metrik parsial. Suatu topologi atas himpunan $\left(U, \ll_{p}\right)$ disebut topologi Alexandrof. Pada tulisan ini ditunjukkan bahwa topologi Alexandrof sama dengan topologi metrik parsial jika didefinisikan bola buka yang tepat dan juga dibuktikan bahwa jika $\mathcal{T}[p]$ adalah topologi metrik parsial maka $\mathcal{T}[p]$ merupakan $T_{0}$-ruang.
\end{abstract}

Kata Kunci: Metrik parsial, nonzero self-distance, topologi metrik parsial, $T_{0}$-ruang, topologi Alexandrof.

\section{Pendahuluan}

Suatu ruang topologi yang didalamnya berlaku fungsi metrik parsial disebut sebagai topologi metrik parsial. Topologi metrik parsial dinotasikan dengan $\mathcal{T}[P]$. Metrik parsial pada himpunan $U$ adalah fungsi $p: U \times U \rightarrow \mathbb{R}$ sedemikian sehingga

(P1) $\forall x, y \in U, x=y \Leftrightarrow p(x, x)=p(x, y)=p(y, y)$

(P2) $\forall x, y \in U, p(x, x) \leq p(x, y)$

(P3) $\forall x, y \in U, p(x, y)=p(y, x)$

(P4) $\forall x, y, z \in U, p(x, z) \leq p(x, y)+p(y, z)-p(y, y)$.

Fungsi metrik parsial merupakan generalisasi minimal dari aksioma metrik sedemikan sehingga untuk setiap $x \in U, d(x, x)$ tidak perlu harus nol, dimana dalam istilah lain dikenal sebagai nonzero self-distance. Aksioma yang diperoleh dari generalisasi tersebut adalah aksioma P2.

Salah satu ruang topologi dinotasikan dengan $T_{0}$-ruang. Menarik untuk dikaji, kaitan antara topologi metrik parsial dengan ruang topologi khususnya $T_{0}$-ruang. 
Suatu urutan parsial adalah suatu relasi biner $\ll \subseteq U \times U$ yang memenuhi kondisi tertentu. Suatu himpunan yang didalamnya didefinisikan suatu urutan parsial disebut sebagai himpunan urutan parsial. Suatu topologi atas suatu himpunan urutan parsial disebut sebagai Topologi Alexandrof. Menarik untuk dikaji yaitu hubungan antara topologi metrik parsial dengan Topologi Alexandrof.

Dalam paper ini akan dikaji kaitan antara topologi metrik parsial dengan $T_{0^{-}}$ ruang dan juga hubungan antara Topologi metrik parsial dengan Topologi Alexandrof, sebagaimana yang ditulis di [6].

\section{TOPOLOGI METRIK PARSIAL}

Berikut diberikan definisi dari topologi dan ruang topologi.

Definisi 2.1. [1] Misal $U$ adalah suatu himpunan. Suatu topologi $\mathcal{T}$ pada $U$ adalah koleksi subhimpunan-subhimpunan dari $U$ yang masing-masingnya disebut sebagai himpunan buka sedemikian sehingga

(i) himpunan kosong $\emptyset$ dan himpunan $U$ adalah himpunan-himpunan buka,

(ii) irisan dari sejumlah hingga himpunan-himpunan buka adalah suatu himpunan buka,

(iii) gabungan dari setiap koleksi himpunan-himpunan buka adalah suatu himpunan buka.

Himpunan $U$ bersama dengan suatu topologi $\mathcal{T}$ pada $U$ adalah suatu ruang topologi yang ditulis sebagai suatu pasangan terurut $(U, \mathcal{T})$.

Suatu koleksi subhimpunan-subhimpunan $U$ adalah suatu topologi pada $U$ jika koleksi tersebut memuat himpunan kosong dan $U$, dan jika sejumlah hingga irisan dan sebarang gabungan himpunan-himpunan di koleksi juga di koleksi. Untuk penyederhanaan notasi, selanjutnya ruang topologi $(U, \mathcal{T})$ ditulis sebagai $U$ saja, kecuali bilamana dinyatakan khusus.

Definisi 2.2. [2]

(1) Suatu subhimpunan $G$ dari $\mathbb{R}$ adalah buka di $\mathbb{R}$ jika untuk setiap $x \in G$ terdapat suatu lingkungan $V$ dari $x$ sedemikian sehingga $V \subseteq G$.

(2) Suatu subhimpunan $F$ dari $\mathbb{R}$ adalah tutup di $\mathbb{R}$ jika komplemen $b(F)=\mathbb{R} \backslash F$ adalah buka di $\mathbb{R}$.

Teorema berikut menjelaskan syarat perlu dan syarat cukup suatu himpunan merupakan himpunan buka.

Teorema 2.3. [1] Misal U suatu ruang topologi dan A adalah subhimpunan dari $U$. Himpunan $A$ adalah suatu himpunan buka di $U$ jika dan hanya jika untuk setiap $x \in A$, terdapat lingkungan $V$ dari $x$ sedemikian sehingga $x \in V \subset A$.

Bukti. $(\Rightarrow)$ Misal himpunan $A$ adalah himpunan buka di $U$ dan $x \in A$. Jika dimisalkan $V=A$ maka $V$ adalah suatu lingkungan dari $x$ sehingga $x \in V \subset A$. $(\Leftarrow)$ Sekarang anggap untuk setiap $x \in A$ terdapat lingkungan $V_{x}$ dari $x$ sedemikian 
sehingga $x \in V_{x} \subset A$. Himpunan $A$ adalah gabungan dari subhimpunan $V_{x}$ dimana $A=\bigcup_{x \in A} V_{x}$. Jadi $A$ adalah gabungan dari himpunan-himpunan buka yang juga adalah himpunan buka.

Definisi 2.4. [1] Misal $U$ adalah himpunan dan $\mathfrak{B}$ adalah koleksi subhimpunansubhimpunan dari $U$. Himpunan $\mathfrak{B}$ adalah basis (dari suatu topologi) pada $U$, jika pernyataan berikut berlaku

(i) untuk setiap $x$ anggota $U$, terdapat himpunan $S$ di $\mathfrak{B}$ sedemikian sehingga $x$ anggota $S$.

(ii) jika himpunan $S_{1}$ dan $S_{2}$ di $\mathfrak{B}$ dan $x \in S_{1} \cap S_{2}$ maka terdapat himpunan $S_{3}$ di $\mathfrak{B}$ sedemikian sehinga $x \in S_{3} \subset S_{1} \cap S_{2}$.

Himpunan-himpunan di $\mathfrak{B}$ disebut sebagai elemen-elemen basis.

Lema 2.5. Lema Gabungan [1] Misal X himpunan dan $\mathcal{C}$ koleksi subhimpunansubhimpunan $X$. Asumsikan untuk setiap $x \in X$, terdapat himpunan $A_{x}$ di $\mathcal{C}$ sedemikian sehingga $x \in A_{x}$. Maka $\bigcup_{x \in X} A_{x}=X$.

Bukti. Akan dibuktikan $\bigcup A_{x} \subset X$ dan $X \subset \bigcup A_{x}$. Pertama, karena setiap $A_{x}$ subhimpunan $X$. Maka jelas bahwa $\bigcup A_{x} \subset X$. Selanjutnya anggap $y \in X$. Terdapat $A_{y} \in \mathcal{C}$ sedemikian sehingga $y \in A_{y}$. Jadi $y \in A_{y} \subset \bigcup A_{x}$. Karena $y \in X$ berakibat $y \in \bigcup A_{x}$, berarti $X \subset \bigcup A_{x}$. Oleh karena itu $\bigcup A_{x}=X$.

Lema 2.6. [1] Misal $\mathfrak{B}$ basis. Asumsikan $B_{l}, \ldots, B_{n} \in \mathfrak{B}$ dan $x \in \bigcap_{i=1}^{n} B_{i}$. Maka terdapat $B^{\prime} \in \mathfrak{B}$ sedemikian sehingga $x \in B^{\prime} \subset \bigcap_{i=1}^{n} B_{i}$.

Bukti. Akan dibuktikan pernyataan terdapat $B^{\prime} \in \mathfrak{B}$ sedemikian sehingga $x \in$ $B^{\prime} \subset \bigcap_{i=1}^{n} B_{i}$ dengan menggunakan prinsip induksi matematika, dimulai dari $n=2$.

(i) Untuk $n=2$ jelas bahwa kasus berlaku dengan menggunakan definisi basis (Definisi 3(ii)).

(ii) Asumsikan pernyataan benar untuk $n-1$ yaitu terdapat $B^{*} \in \mathfrak{B}$ sedemikian sehingga $x \in B^{*} \subset \bigcap_{i=1}^{n} B_{i}$.

Akan ditunjukkan pernyataan benar untuk $n$. Dengan hipotesis lema dan hipotesis induksi maka $x \in B^{*} \cap B_{n}$. Oleh karena itu dengan Definisi 3(ii) terdapat $B^{\prime} \in \mathfrak{B}$ sedemikian sehingga $x \in B^{\prime} \subset B^{*} \cap B_{n}$. Karena $B^{*} \subset \bigcap_{i=1}^{n-1} B_{i}$ sehingga $x \in B^{\prime} \subset \bigcap_{i=1}^{n} B_{i}$. Jadi pernyataan benar.

Definisi 2.7. [1] Misal $\mathfrak{B}$ adalah basis pada himpunan $U$. Topologi yang dibangun oleh $\mathfrak{B}$ adalah diperoleh dengan mendefinisikan himpunan-himpunan di topologi tersebut sebagai himpunan kosong dan setiap himpunan di topologi tersebut sama dengan gabungan dari elemen-elemen basis.

Teorema 2.8. [1] Topologi $\mathcal{T}$ yang dibangun oleh suatu basis $\mathfrak{B}$ adalah suatu topologi.

Bukti. Berdasarkan Definisi 4, himpunan kosong $\emptyset$ ada di $\mathcal{T}$. Karena setiap titik di $U$ termuat di elemen basis, maka $U$ adalah gabungan dari semua elemen-elemen 
basis dan oleh karena itu berada di $\mathcal{T}$. Selanjutnya akan ditunjukkan bahwa irisan terhingga dari himpunan-himpunan di $\mathcal{T}$ berada di $\mathcal{T}$. Misal $V=U_{1} \cap U_{2} \cap \ldots \cap U_{n}$ dimana setiap $U_{i}$ ada di $\mathcal{T}$ untuk $i \in \mathbb{N}$. Jika untuk setiap $U_{i}, i \in \mathbb{N}$ adalah himpunan kosong maka $V$ juga himpunan kosong, dan $V$ ada di $\mathcal{T}$. Jadi asumsikan bahwa $U_{i}$ adalah gabungan dari elemen-elemen basis. Akan ditunjukkan $V$ adalah gabungan dari elemen-elemen basis. Misal $x \in V$ sebarang. Maka $x \in U_{i}$ untuk setiap $i \in \mathbb{N}$. Karena $U_{i}$ adalah gabungan dari elemen basis, terdapat suatu elemen basis $B_{i}, i \in \mathbb{N}$ sedemikian sehingga $x \in B_{i} \subset U_{i}$ untuk setiap $i \in \mathbb{N}$. Maka $x \in \bigcap_{i=1}^{n} B_{i}$. Oleh karena itu dengan Lema 2, terdapat suatu elemen basis $B_{x}$ sedemikian sehingga $x \in B_{x} \subset \bigcap_{i=1}^{n} B_{i} \subset V$. Ini mengikuti Lema 1 , bahwa $V=\bigcup_{x \in V} B_{x}$, dan oleh karena itu $V$ adalah suatu gabungan dari elemen-elemen basis. Jadi irisan terhingga himpunan-himpunan di $\mathcal{T}$ berada di $\mathcal{T}$.

Definisi 2.9. [6] Suatu bola buka dari ruang metrik parsial (U,p) adalah suatu himpunan dengan bentuk

$$
B_{\varepsilon}^{p}(x)=\{y \in U \mid p(x, y)<\varepsilon\}
$$

untuk setiap $\varepsilon>0$ dan $x \in U$.

Persamaan (1) menyatakan suatu bola buka dari ruang metrik parsial. Berdasarkan Teorema 3 suatu topologi dari ruang metrik parsial didefinisikan sebagai berikut.

Definisi 2.10. Misal $(U, p)$ adalah ruang metrik parsial. Topologi yang dihasilkan oleh basis bola buka metrik parsial $\mathfrak{B}=\left\{B_{\varepsilon}^{p}(x) \mid x \in U, \varepsilon>0\right\}$ disebut sebagai topologi yang diinduksi oleh $p$ dan dikenal sebagai suatu topologi metrik parsial $\mathcal{T}[p]$.

Jika diberikan metrik parsial pada suatu himpunan $U$, suatu topologi pada himpunan $U$ didefinisikan melalui bola buka yang ditentukan oleh metrik parsial tersebut. Berdasarkan Definisi 6, suatu topologi dihasilkan oleh basis bola buka metrik parsial. Untuk itu akan ditunjukkan bahwa suatu koleksi dari bola buka metrik parsial adalah basis dari suatu topologi $\mathcal{T}[p]$. Namun sebelumnya diberikan suatu teorema yang menunjukkan bahwa jika suatu titik $x$ berada di bola buka $B_{\varepsilon}^{p}(a)$, maka terdapat suatu bola buka yang berpusat di $x$ di $B_{\varepsilon}^{p}(a)$.

Teorema 2.11. [6] Untuk setiap bola-bola buka $B_{\varepsilon}^{p}(a)$ dari ruang metrik parsial $(U, p)$, dan $x \in B_{\varepsilon}^{p}(a)$, terdapat $\delta>0$ sedemikian sehingga $x \in B_{\delta}^{p}(x) \subseteq B_{\varepsilon}^{p}(a)$.

Bukti. Ambil $x \in B_{\varepsilon}^{p}(a)$. Akan ditunjukkan terdapat $\delta>0$ sedemikian sehingga $x \in B_{\delta}^{p}(x) \subseteq B_{\varepsilon}^{p}(a)$. Misal $x \in B_{\varepsilon}^{p}(a)$, dengan Definisi $5 p(a, x)<\varepsilon, \forall x \in U$. Misal $\delta=\varepsilon-p(a, x)+p(x, x)$. Maka $\delta>0$ karena $\varepsilon>p(a, x)$. Juga $\delta>p(x, x)$ karena $\varepsilon>p(a, x)$. Jadi $x \in B_{\delta}^{p}(x)$. Sekarang akan ditunjukkan bahwa $B_{\delta}^{p}(x) \subseteq B_{\varepsilon}^{p}(a)$. Ambil $y \in B_{\delta}^{p}(x)$, akan ditunjukkan $y \in B_{\varepsilon}^{p}(a)$. Karena $y \in B_{\delta}^{p}(x)$ berarti $p(x, y)<$ $\delta$ (Berdasarkan Definisi 5). Perhatikan bahwa

$$
\begin{aligned}
& y \in B_{\delta}^{p}(x) \text { dan } p(x, y)=p(y, x)(\text { dari }(\mathrm{P} 2)) \text { maka } p(y, x)<\delta \\
& \Leftrightarrow p(y, x)<\varepsilon-p(x, a)+p(x, x)
\end{aligned}
$$




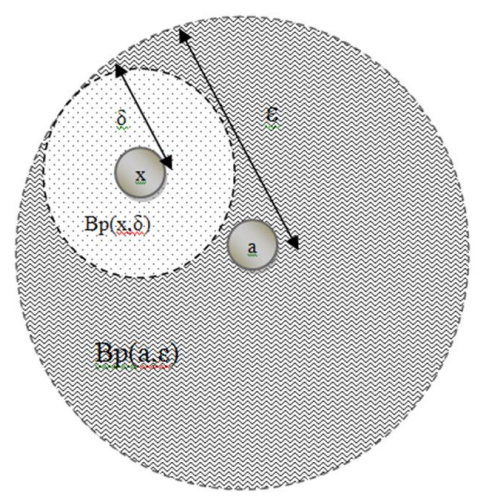

Gambar 1. Terdapat suatu bola buka metrik parsial didalam bola buka metrik parsial yang lain

$$
\begin{aligned}
& \Leftrightarrow p(y, x)+p(x, a)-p(x, x)<\varepsilon(\text { dengan }(\mathrm{P} 4)) \\
& \Leftrightarrow p(y, a)<\varepsilon .
\end{aligned}
$$

Karena $p(y, a)<\varepsilon$ maka $y \in B_{\varepsilon}^{p}(a)$. Karena $y \in B_{\delta}^{p}(x)$ dan $y \in B_{\varepsilon}^{p}(a)$ maka terbukti bahwa $x \in B_{\delta}^{p}(x) \subseteq B_{\varepsilon}^{p}(a)$.

Karena $\forall \varepsilon>0, \delta>0$ dan $a, x \in U, x \in B_{\delta}^{p}(x) \subseteq B_{\varepsilon}^{p}(a)$. Maka berdasarkan Teorema 1, jelas bahwa untuk setiap bola buka metrik parsial merupakan suatu himpunan buka. Oleh karena itu berdasarkan Definisi 2, Persamaan (1) dapat dinyatakan sebagai suatu lingkungan dari titik $x$. Jadi bola buka dari ruang metrik parsial $B_{\varepsilon}^{p}(x)=\{y \in U \mid p(x, y)<\varepsilon\}$ dimana $x \in U$ dan $\varepsilon>0$ merupakan suatu lingkungan dari titik $x$.

Teorema 2.12. [6] Himpunan semua bola buka dari suatu ruang metrik parsial $p: U \times U \rightarrow \mathbb{R}$ adalah basis dari suatu ruang topologi $(U, \mathcal{T}[p])$.

Bukti. Misal $\mathfrak{B}$ adalah koleksi bola buka dari metrik parsial

$$
\mathfrak{B}=\left\{B_{\varepsilon}^{p}(a) \mid a \in U, \varepsilon>0\right\} .
$$

Akan ditunjukkan $\mathfrak{B}$ adalah basis dari suatu topologi $\mathcal{T}$. Berdasarkan Definisi 3, $\mathfrak{B}$ adalas basis dari ruang topologi $(U, \mathcal{T}[p])$ dengan menujukkan

(i) untuk setiap $x \in U$, terdapat himpunan $S$ di $\mathfrak{B}$ sedemikian sehingga $x \in S$. Misal $x \in U$. Akan ditunjukkan bahwa terdapat himpunan $S$ di $\mathfrak{B}$ sedemikian sehingga $x \in S$. Untuk setiap bola buka $B_{\varepsilon}^{p}(a)$ dan $x \in B_{\varepsilon}^{p}(a)$ ada $\delta=\varepsilon-$ $p(x, a)+p(x, x)$ sedemikian sehingga $x \in B_{\delta}^{p}(x)$. Misal himpunan $S$ adalah himpunan bola buka $B_{\delta}^{p}(x) \subseteq B_{\varepsilon}^{p}(a)$. Berdasarkan Teorema 4 , jelas bahwa setiap titik-titik $x \in U$ termuat dalam suatu himpunan $S$.

(ii) untuk setiap himpunan bola-bola buka $B_{\varepsilon}^{p}(x)$ dan $B_{\delta}^{p}(y)$ di $\mathfrak{B}$ dan $x \in$ $B_{\varepsilon}^{p}(x) \cap B_{\delta}^{p}(y)$. Akan ditunjukkan bahwa terdapat himpunan $B_{3}$ di $\mathfrak{B}$ sedemikian sehingga $x \in B_{3} \subset B_{\varepsilon}^{p}(x) \cap B_{\delta}^{p}(y)$. 


$$
B_{\varepsilon}^{p}(x) \cap B_{\delta}^{p}(y)=\cup\left\{B_{\eta}^{p}(z) \mid z \in B_{\varepsilon}^{p}(x) \cap B_{\delta}^{p}(y)\right\} .
$$

Berdasarkan Teorema 4 terdapat $\eta$ dimana $\eta=\min \{\delta-p(y, z), \varepsilon-p(x, z)+$ $p(z, z)\}$ sedemikian sehingga $z \in B_{\eta}^{p}(z)=B_{3} \subset B_{\varepsilon}^{p}(x) \cap B_{\delta}^{p}(y)$.

Oleh karena itu, $\mathfrak{B}=\left\{B_{\varepsilon}^{p}(a) \mid a \in U, \varepsilon>0\right\}$ adalah basis dari suatu topologi $\mathcal{T}[p] . \square$

Teorema 2.13. [6] Setiap topologi metrik parsial adalah $T_{0}$-ruang.

Bukti. Misal $p: U \times U \rightarrow \mathbb{R}$ adalah metrik parsial dan $\mathfrak{B}=\left\{B_{\varepsilon}^{p}(a) \mid a \in U, \varepsilon>0\right\}$ adalah basis dari suatu topologi metrik parsial $\mathcal{T}[p]$ atas $U$. Untuk setiap $x, y \in U$ dimana $x \neq y$, maka $p(x, x)<p(x, y)$. Misalkan $x \in B_{\varepsilon}^{p}(a)$ Berdasarkan Teorema 4 terdapat lingkungan $B_{\delta}^{p}(x)$ di $\mathcal{B}$, dimana $\delta=\frac{p(x, x)+p(x, y)}{2}$. Untuk setiap $p(x, x), p(x, y) \in \mathbb{R}$, karena $p(x, x)<p(x, y)$ maka $p(x, x)<\frac{p(x, x)+p(x, y)}{2}<$ $p(x, y)$. Sehingga diperoleh $x \in B_{\delta}^{p}(x)$ dan $y \notin B_{\delta}^{p}(x)$. Oleh karena itu topologi $\mathcal{T}[p]$ atas $U$ merupakan $T_{0}$-ruang.

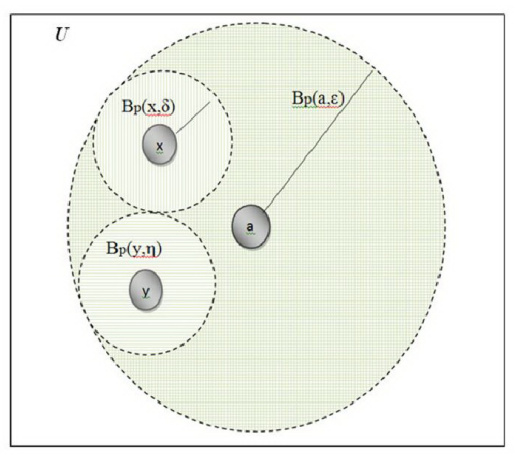

Gambar 2. Ruang Topologi yang merupakan $T_{0}$-ruang

Secara sederhana, Teorema 6 menyatakan bahwa setiap titik-titik di $U$ dapat dibedakan dengan suatu bola buka yang merupakan tempat titik tersebut berada. Berikut ini diberikan hubungan antara relasi urutan parsial $\ll_{p}$ dengan fungsi metrik parsial.

Definisi 2.14. [4] Suatu urutan parsial adalah suatu relasi biner $\ll \subseteq U \times U$ sedemikian sehingga (PO1) $\forall x \in U, x \ll x$

(PO2) $\forall x, y \in U, x \ll y$ dan $y \ll x \Rightarrow x=y$

(PO3) $\forall x, y, z \in U, x \ll y$ dan $y \ll z \Rightarrow x \ll z$.

Suatu himpunan urutan parsial adalah pasangan terurut $(U, \ll)$ sedemikian sehingga $\ll$ adalah urutan parsial pada himpunan $U$.

Definisi 2.15. [4] Suatu Topologi Alexandrof atas suatu himpunan urutan parsial $(U, \ll)$ adalah suatu topologi $\mathcal{T}$ atas $U$ sedemikian sehingga 


$$
\forall \mathcal{O} \in \mathcal{T} \text { dan } x, y \in U \text {, jika } x \in \mathcal{O} \text { dan } x \ll y \Rightarrow y \in \mathcal{O} .
$$

Definisi 2.16. [6] Untuk setiap metrik parsial $p: U \times U \rightarrow \mathbb{R}, \ll_{p} \subseteq U \times U$ adalah relasi biner sedemikian sehingga

$$
\forall x, y \in U, x \ll_{p} y \Leftrightarrow p(x, x)=p(x, y) .
$$

Suatu relasi biner « telah dijelaskan pada Definisi 7. Berikut ini dijelaskan relasi $\ll_{p}$ sebagai suatu urutan parsial pada ruang metrik parsial.

Teorema 2.17. [6] Untuk setiap metrik parsial $p, \ll_{p}$ adalah urutan parsial.

Bukti. Misal $\ll_{p}$ relasi biner pada ruang metrik parsial $(U, p)$. Akan ditunjukkan $\ll_{p}$ adalah urutan parsial. Berdasarkan Definisi $7, \ll_{p}$ adalah urutan parsial dengan menunjukkan bahwa (PO1)-(PO3) terpenuhi.

(1) Akan ditunjukkan bahwa (PO1) terpenuhi. Ambil $x \in U$, karena Definisi 8 maka $p(x, x)=p(x, x)$.

(2) Akan ditunjukkan bahwa (PO2) terpenuhi. Ambil $x, y \in U$ dan misalkan $x \ll_{p} y$ dan $y \ll_{p} x$ maka dengan $(\mathrm{P} 3), p(x, x)=p(x, y)=p(y, y)$ sehingga dengan $P 1$ diperoleh $x=y$.

(3) Akan ditunjukkan bahwa (PO3) terpenuhi. Ambil $x, y, z \in U$ dimana $x \ll_{p} y$ dan $y \ll_{p} z$. Jika $x \ll_{p} y$ berarti $p(x, x)=p(x, y)$ dan jika $y \ll_{p} z$ berarti $p(y, y)=p(y, z)$. Berdasarkan $(\mathrm{P} 4), p(x, z) \leq p(x, y)+p(y, z)-p(y, y)$. Karena $p(y, y)=p(y, z)$ maka $p(x, z) \leq p(x, x)$. Karena $(\mathrm{P} 2)$ maka $p(x, z)=p(x, x)$. Berdasarkan Definisi 9, diperoleh bahwa $x \ll_{p} z$.

Oleh karena itu $\ll_{p}$ adalah urutan parsial.

Himpunan yang memuat urutan parsial $p, \ll_{p}$ disebut sebagai himpunan urutan parsial $p$ dinotasikan dengan $\left(U, \ll_{p}\right)$. Berdasarkan Definisi 8, suatu Topologi Alexandrof atas himpunan urutan parsial $\left(U, \ll_{p}\right)$ adalah suatu topologi $\mathcal{T}$ atas $U$ sedemikian sehingga

$\forall \mathcal{S} \in \mathcal{T}$ dan $x, y \in U$, jika $x \in \mathcal{S}$ dan $x \ll_{p} y \Leftrightarrow p(x, x)=p(x, y) \Rightarrow y \in \mathcal{S}$.

Teorema berikut menjelaskan bagaimana hubungan antara Topologi metrik parsial $\mathcal{T}[p]$ dengan Topologi Alexandrof $\mathcal{T}\left[\ll_{p}\right]$.

Teorema 2.18. [6] Untuk setiap metrik parsial $p, \mathcal{T}[p] \subseteq \mathcal{T}\left[\ll_{p}\right]$.

Bukti. Ambil sebarang bola buka $B_{\varepsilon}^{p}(x)$ di $\mathcal{T}[p]$. Artinya ambil sebarang $x \in U$ dan $\varepsilon>0$. Akan ditunjukkan bahwa $\mathcal{T}[p] \subseteq \mathcal{T}\left[\ll_{p}\right]$. Untuk itu harus ditunjukkan bahwa

$$
\forall x, y \in B_{\varepsilon}^{p}(x) \text { berlaku } y \ll_{p} z .
$$

Diketahui bahwa karena $(\mathrm{P} 4), p(x, z) \leq p(x, y)+p(y, z)-p(y, y)$. Perhatikan bahwa $p(x, z)<\varepsilon \Leftrightarrow p(y, z)-p(y, y)=0 \Leftrightarrow y \ll_{p} z$.

Oleh karena itu terbukti bahwa $\mathcal{T}[p] \subseteq \mathcal{T}\left[\ll_{p}\right]$. 
Teorema 2.19. [6] Untuk setiap metrik parsial $p, p: U \times U \rightarrow \mathbb{R}, \mathcal{T}\left[\ll_{p}\right]=\mathcal{T}[p]$ jika dan hanya jika

$$
\forall x \in U, \exists \varepsilon>0, B_{\varepsilon}^{p}(x)=\left\{y \mid x \ll_{p} y\right\}
$$

Bukti. $\Leftarrow$ Anggap bahwa untuk setiap $x \in U, \exists \varepsilon>0, B_{\varepsilon}^{p}(x)=\left\{y \mid x \ll_{p} y\right\}$. Maka untuk setiap $\mathcal{O} \in \mathcal{T}\left[\ll_{p}\right]$, dimana $\mathcal{T}\left[\ll_{p}\right]=\{\mathcal{O} \subseteq U \mid \forall x \in \mathcal{O}, x \ll y \Rightarrow y \in \mathcal{O}\}=$ $\left\{y \mid x \ll_{p} y\right\}$

$$
\begin{gathered}
\mathcal{O}=\bigcup_{x \in \mathcal{O}}\left\{y \mid x \ll_{p} y\right\}=\bigcup_{x \in \mathcal{O}} B_{\varepsilon}^{p}(x) \in \mathcal{T}[p], \\
\text { sehingga diperoleh bahwa } \mathcal{T}\left[\ll_{p}\right] \subseteq \mathcal{T}[p]
\end{gathered}
$$

Berdasarkan Teorema 8, maka $\mathcal{T}\left[\ll_{p}\right]=\mathcal{T}[p]$.

$\Rightarrow$ Anggap bahwa $\mathcal{T}\left[\ll_{p}\right]=\mathcal{T}[p]$. Maka $\forall x \in U,\left\{y \mid x \ll_{p} y\right\} \in \mathcal{T}[p]$. Jadi dengan Teorema $4, \forall x \in U, \exists \varepsilon>0, x \in B_{\varepsilon}^{p}(x) \subseteq\left\{y \mid x \ll_{p} y\right\}$. Tapi jika $x \in B_{\varepsilon}^{p}(x)$ maka $\left\{y \mid x \ll_{p} y\right\} \subseteq B_{\varepsilon}^{p}(x)$. Jadi

$$
\forall x \in U, \exists \varepsilon>0, B_{\varepsilon}^{p}(x)=\left\{y \mid x \ll_{p} y\right\} .
$$

Jadi hubungan antara Topologi metrik parsial $\mathcal{T}[p]$ dengan Topologi alexandrof $\mathcal{T}\left[\ll_{p}\right]$ dijelaskan pada Teorema 8 dan Teorema 9 .

\section{Ucapan Terima kasih}

Penulis mengucapkan terima kasih kepada Bapak Dr. Admi Nazra, Bapak Efendi, M.Si, Bapak Zulakmal, M.Si, Ibu Dr. Lyra Yulianti, dan Ibu Hazmira Yozza, M.Si yang telah memberikan masukan dan saran sehingga paper ini dapat diselesaikan dengan baik.

\section{Daftar Pustaka}

[1] Adams, Colin dan Robert Franzosa. 2008. Introduction to Topology Pure and Applied. Pearson Education, India

[2] Bartle, Robert. G dan Donald R. Sherbert. 1994. Introduction to Real Analysis. Second edition. Eastern Michigan University, Singapore

[3] Bredon, Glen.E. 1993. Topology and Geometry. Springer Verlag, New York

[4] Matthews, S.G. 1992. Partial metric spaces. The Mathematical Asociation Of America. 116 : 708-718

[5] Matthews, S.G. 2008. Partial Metric Spaces A Fuss About Nothing. Konferensi di Universitaria de la UNAM Mexico City, tidak diterbitkan.

[6] Matthews, S.G. 1992. Partial metric topology. Annals of the New York Academy of Sciences. $728: 183-197$ 